УДК 347.948

DOI: $10.35750 / 2071-8284-2019-3-130-135$

\author{
Д.Н. Жидков \\ кандидат юридических наук \\ Санкт-Петербургский университет МВД России \\ Российская Федерация, 198206, Санкт-Петербург, ул. Лётчика Пилютова, д. 1 \\ ORCID: 0000-0003-2135-9234.E-mail:dmitry_jidkov@mail.ru

\section{Личный кабинет эксперта Экспертно-криминалистического центра МВД Российской Федерации}

\begin{abstract}
Аннотация: В статье предлагается создание в рамках ИСОД МВД России личных электронных кабинетов для сотрудников правоохранительных органов, способных разрешить пробелы в методическом обеспечении служебной деятельности. Рассматриваются основные проблемные направления методического обеспечения профессиональной деятельности сотрудников экспертных подразделений. Частично в статье затронуты вопросы организации методического обеспечения новых актуальных видов судебных экспертиз, таких как строительно-техничекие, видеотехнические, автотехнические, компьютерные, радиотехнические; описаны основные функциональные возможности единой системы информационно-аналитического обеспечения деятельности МВД России (ИСОД МВД). Автором отмечено, что один из основных критериев, которым должны соответствовать виртуальные кабинеты экспертов ОВД, - это актуальная информация. Предложено отражать в личных кабинетах следующую информацию: сведения об имеющихся у сотрудников подтверждённых допусках на самостоятельное производство судебных экспертиз; сведения о повышении квалификаций с возможностью их повышения в режиме on-line; актуальная информация о новейших и уже существующих экспертных методиках, на право производства которых у эксперта имеются подтвержденные допуски; информация о приборной базе по каждому виду экспертиз, на которые имеется активный допуск (с указанием ближайшего в субъекте местонахождения); электронная библиотека литературы, в том числе секретной, соответствующей уровню допуска к ней у эксперта, с возможностью ознакомления; электронные коллекции криминалистических объектов (по возможности 3D-модели), с примерами их описаний, основными особенностями и в некоторых случаях функциональным назначением, точными размерами и признаками.

Ключевые слова: методическое обеспечение, правоохранительные органы, судебные эксперты, личный кабинет, единая система информационно-аналитического обеспечения деятельности МВД России.
\end{abstract}

Для ичитирования: Жидков Д.Н. Личный кабинет эксперта Экспертно-криминалистического центра МВД Российской Федерации // Вестник Санкт-Петербургского университета МВД России. - 2019. - № 3 (83). - С. 130-135. DOI: 10.35750/2071-8284-2019-3-130-135.

Dmitry T. Jidkov

Cand. Sci. (Jurid.)

Saint-Petersburg University of the MIA of Russia

1, Letchika Pilyutova str., Saint-Petersburg, 198206, Russian Federation

ORCID:/0000-0003-2135-9234.E-mail:dmitry_jidkov@mail.ru

\title{
A personal account of the expert of the Ministry of Internal Affairs of the Russian Federation
}

Annotation: The article proposes the creation of personal electronic offices within the ISOD of the Ministry of internal Affairs of Russia for law enforcement officers who are able to solve gaps in the methodological support of official activities. The basic problem directions of methodical maintenance 
of professional activity of employees of expert divisions are considered. Part of the article deals with the organization of methodological support of new relevant types of forensic examinations, such as: construction and technical, video, automotive, computer, radio, describes the basic functionality of a single system of information and analytical support of the Ministry of internal Affairs of the Russian Federation (ISOD MIA). The author noted that one of the main criteria, the presence of which must necessarily be contained in the virtual offices of ATS experts is relevant information. So it is offered to reflect in private offices the following information: data on the tolerances available for the employee on independent production of judicial examinations; data on improvement of qualifications, with possibility of their increase in the mode on-line; actual information on the latest and already existing techniques on examinations on the right of production of which the expert has the confirmed admissions; information on instrument base on each type of examinations on which there is an active admission (with indication of the nearest availability); electronic library of literature, including secret, corresponding to the level of admission to it from the expert, with the possibility of acquaintance; electronic collections of forensic objects (if possible 3D models), with examples of their descriptions, the main features and in some cases the functional purpose, the exact size.

Keywords: methodical support, law enforcement, expert staff, personal cabinet, United System of Informational Analitic Suppotment of Activity.

For citation: Jidkov D.T. A personal account of the expert of the the Ministry of Internal Affairs of the Russian Federation // Vestnik of St. Petersburg University of the Ministry of Internal Affairs of Russia. - 2019. - № 3 (83). - P. 130-135. DOI: 10.35750/2071-8284-2019-3-130-135.

В системе подготовки сотрудников для экспертных подразделений системы ЭКЦ МВД России имеется серьёзная проблема - программы дополнительного профессионального обучения слабо адаптируются к условиям стремительного научно-технического прогресса. Это связано с постоянным появлением новых и новых видов экспертиз и исследований, экспертных методик, а также с открытием новых криминалистически значимых объектов или новых свойств ранее изученных [1].

Сегодня судебно-экспертные подразделения системы МВД России столкнулись с беспрецедентным по своим масштабам влиянием научно-технического прогресса. Многие преступники, а также преступные группы и сообщества зачастую пользуются последними его достижениями.

В экспертных подразделениях системы Министерства юстиции данная проблема тоже не исследуется, однако, по нашему мнению, в связи с грядущим принятием Федерального закона «О судебно-экспертной деятельности в Российской Федерации» ${ }^{1}$, в котором, возможно, немалую роль отведут экспертам Министерства юстиции необходимо уже сейчас начать прора-

${ }^{1} \mathrm{O}$ судебно-экспертной деятельности в Российской Федерации : Проект федерального закона № 306504-6 [Электронный ресурс] // СПС «Гарант». - Режим доступа:: http://mobileonline.garant.ru/\#/document/57731874/ paragraph/98/highlight/\%D0 (дата обращения: 27.11.2018). батывать вопрос о едином информационно-методическом обеспечении российских судебных экспертов [2]. Возможно, вскоре после принятия нового Федерального закона ${ }^{2}$ изменится и ситуация со сложившейся разницей в подходах к методикам производства отдельных видов и родов экспертиз, хотя данная проблема обсуждается в научных кругах уже более 40 лет. Сегодня экспертам различных ведомств необходимо объединить усилия с целью доработки проекта Федерального закона о судебно-экспертной деятельности, уделив внимание методическому обеспечению профессиональной деятельности экспертов-криминалистов. 8 декабря 2018 года Правительством Российской Федерации принято постановление № 1502 «О правительственной комиссии по координации судебно-экспертной деятельности в Российской Федерации», что является серьезным подспорьем для выхода из сложившейся ситуации, однако тем не менее пока ещё не ясно каким же образом будет осуществляться её деятельность на практике.

На основании анализа материалов заседания расширенного состава Научно-практи-

${ }^{2} \mathrm{O}$ государственной судебно-экспертной деятельности в Российской Федерации : Федеральный закон от 31 мая 2001 г. № 73-Ф3 // СПС «Гарант». - Режим доступа: $\quad$ http://mobileonline.garant.ru/\#/document/12123142/ paragraph/4196/highlight/фз\%2073 (дата обращения: 27.11.2018). 
ческой секции Совета Экспертно-криминалистического центра МВД России от 13 ноября 2018 г. наиболее актуальными направлениями развития методического обеспечения служебной деятельности судебных экспертов МВД России являются: развитие методического обеспечения новейших видов судебных экспертиз, а также разработка примерных дополнительных профессиональных программ с возможностью дистанционного обучения специального курса «Основы экспертно-криминалистической деятельности в МВД России» ${ }^{3}$.

Одними из новейших видов судебных экспертиз и исследований, развиваемых сегодня судебными экспертами ЭКЦ МВД России, являются строительно-технические, видеотехнические, автотехнические, компьютерные, радиотехниче-

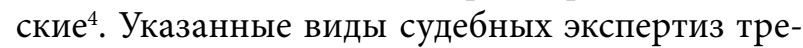
буют актуального методического обеспечения.

По нашему мнению, сегодня вся правоохранительная система мира, в том числе и Российской Федерации, столкнулась с проблемой максимально быстрой актуализации специальных криминалистических знаний. Указанная проблема затрагивает и деятельность экспертно-криминалистических подразделений системы МВД России, одной из задач которых является постоянное исследование новейших криминалистически значимых объектов и следов. Руководство ЭКЦ МВД России уделяет этому направлению должное внимание, проводя немало научных исследований и рассматривая ключевые моменты по их внедрению в служебную практику на ежегодных заседаниях Научнопрактической секции ЭКЦ МВД России.

В данной статье мы предлагаем пересмотреть несовершенные, на наш взгляд, механизмы и способы актуализации специальных знаний сотрудников экспертно-криминалистических подразделений ${ }^{5}$. Основные моменты, связанные с совершенствованием методического обеспечения профессиональной деятельности судебных экспертов, сегодня заключаются в направлении соответствующих информационных материалов, документов, рекомендаций руководителям территориальных экспертных подразделений по почте либо с использованием единой системы инфор-

\footnotetext{
${ }^{3}$ Материалы заседания расширенного состава Научно-практической секции ЭКЦ МВД России. - Москва, 13 ноября 2018 года.

${ }^{4}$ Протокол заседания расширенного состава Научно-практической секции ЭКЦ МВД России от 23 ноября 2017 г. №11.

${ }^{5}$ Там же.
}

мационно-аналитического обеспечения деятельности МВД России (ИСОД МВД) для последующего ознакомления сотрудников подразделений [3], однако в этом случае не учитываются особенности службы судебных экспертов на местах. Зачастую эксперты ЭКЦ МВД России несут службу либо в соответствии с утвержденным графиком $2 / 2$, либо $2 / 1$, либо $1 / 3$, в головных подразделениях - 5/2. Указанное обстоятельство лишает руководителей территориальных подразделений возможности своевременно доводить актуальную информацию по различным видам экспертиз и исследований, причём в связи с современными тенденциями стремительного появления и развития новых видов судебных экспертиз часто у руководителей экспертных подразделений и их сотрудников имеются различные допуски на право самостоятельного производства судебных экспертиз.

Одним из основных направлений научнотехнической политики МВД России является совершенствование единой системы информационно-аналитического обеспечения деятельности (далее ИСОД) МВД России [4]. В апреле 2015 года в системе МВД России введена система ИСОД, в рамках которой действуют несколько прикладных сервисов, направленных на улучшение качества обеспечения различной служебной деятельности органов внутренних дел. По нашему мнению, появление и развитие указанной системы является своевременным, а также, безусловно, действенным инструментом, способствующим актуализации специальных знаний в области получения объективной и всесторонней информации о современных направлениях развития информационно-технологической структуры, аппаратно-программных комплексов, средств связи и специальной техники, разработанных в интересах МВД России [4].

Основное назначение единой технологической платформы - создание информационнотелекоммуникационной инфраструктуры, продуктивной среды для консолидации основных информационных систем МВД России [5].

ИСОД активно внедряется в судебно-экспертные учреждения МВД России. Однако имеющиеся сегодня прикладные сервисы не в полной мере раскрывают потенциал указанной системы.

В связи с обозначенной выше проблемой максимально быстрой необходимости актуализации специальных криминалистических знаний считаем необходимым расширение функциональных возможностей ИСОД МВД России, 


\section{Пример оформления интерфейса рабочего кабинета эксперта-криминалиста в системе ИСОД МВД России}

\begin{tabular}{|c|c|}
\hline $\begin{array}{l}\text { Рабочий кабинет } \\
\text { должность, учёная степень, учёл } \\
\text { специальное звание }\end{array}$ & ввание, \\
\hline Допуски & \\
\hline Повышение квалификации & \\
\hline Методики & \\
\hline $\begin{array}{l}\text { Технико-криминалистическое } \\
\text { обеспечение }\end{array}$ & Основная страница \\
\hline Электронная библиотека & \\
\hline $\begin{array}{l}\text { Криминалистическая } \\
\text { коллекция }\end{array}$ & \\
\hline Обзор НИР & \\
\hline $\begin{array}{l}\text { Справочная информация } \\
\text { заседаний Мс ЭКЦ МВД РФ }\end{array}$ & \\
\hline Журнал «Экспертная практика» & \\
\hline
\end{tabular}

обладающей огромным потенциалом в области актуализации специального методического обеспечения судебно-экспертной деятельности.

Насколько нам известно, по завершении внедрения системы ИСОД предполагается организация доступа к ней каждому сотруднику органов внутренних дел, в том числе и каждому экспертукриминалисту системы МВД России [6].

Далее, в нашей статье мы бы хотели обосновать необходимость создания такого кабинета в рамках системы ИСОД именно для криминалистов ЭКЦ МВД России, который, к примеру, включал бы следующие параметры: «Основная страница», «Допуски», «Повышение квалификации», «Методики», «Технико-криминалистическое обеспечение», «Электронная библиотека», «Криминалистическая коллекция», «Обзор НИР», «Справочная информация заседаний МС ЭКЦ МВД РФ», «Журнал “Экспертная практика"» (см. табл. 1).

Так, выделенный нами пункт меню представленного рабочего кабинета «Допуски» позволит эксперту-криминалисту отслеживать периодичность подтверждения имеющихся у него допусков на самостоятельное производство различных судебных экспертиз, что позволит сократить круг обязанностей сотрудников методических отделов территориальных ЭКП, ведущих учёт данной информации в головных подразделениях ЭКЦ субъектов Российской Федерации. Считаем, что эта информация должна вносится в систему один раз, и только представителями образовательных организаций, в которых сотрудниками и были получены допуски на самостоятельное производство судебных экспертиз.

При этом данное вложение должно обязательно включать сведения о дате подтверждения криминалистического допуска, обладать электронной формой, способной в случае необходимости подгружать учебные экспертизы и иллюстративные таблицы к ним с целью самостоятельного подтверждения допусков, а также обеспечения максимально быстрого реагирования на замечания в рецензиях по отправленным на рецензирование материалам. Данная мера существенно сократит сроки подтверждения экспертных допусков, так как у каждого эксперта появится возможность в минимальное время отправить экспертизы на рецензирование и так же быстро получить его результаты и ознако- 
миться с ними, минуя стандартные процедуры отправки такой документации.

Закладка «Повышение квалификации» должна содержать сведения о повышении квалификаций сотрудниками с возможностью их повышения в режиме on-line, дистанционно. Эта функция вводится в первую очередь в связи с необходимостью экономии государственных средств. Мы считаем возможным централизованное повышение квалификации в дистанционном режиме, тем более что такие возможности уже сейчас имеются в системе ИСОД МВД России, в рамках которой постоянно проводятся различные видеоконференции.

Одно из основных требований к информации, размещаемой в рассматриваемых виртуальных кабинетах экспертов - её актуальность. Здесь должна размещаться информация:

- о новейших (с системой оповещения о них) и уже существующих методиках по экспертизам, на право производства которых у эксперта имеются активные допуски;

- о приборной базе по каждому виду экспертиз, на которые имеется активный допуск у эксперта (с указанием его ближайшего наличия в субъекте). По нашему мнению, назрела необходимость в производстве анализа лабораторной базы учреждений и организаций, не входящих в систему МВД России, но способных её предоставлять при необходимости проведения различных экспертиз и исследований;

- электронная библиотека актуальной литературы, в том числе секретной, соответствующей уровню допуска к ней у эксперта, с возможностью ознакомления в связи с тем, что только таким образом можно получать максимально оперативно всю интересующую информацию, находясь в любом регионе Российской Федерации;

- электронные коллекции криминалистических объектов (по возможности 3D-моделей) с примерами их описаний, основными особенностями и в некоторых случаях функциональным назначением, точными размерами.

Считаем возможным создание аналогичных кабинетов и для других сотрудников ОВД, в том числе и преподавателей образовательных организаций системы МВД России [1], но с учётом направлений их служебной деятельности.

Также мы предлагаем создать по каждому из выделенных направлений форум с обратной связью для on-line общения, возможно, с видеосвязью со специалистами ЭКЦ МВД России для консультаций по вопросам производства экспертиз и методик, исключающий ненужный документооборот по этому направлению, что позволит выявлять проблемы, тенденции и актуальные направления в развитии судебно-экспертной деятельности, в том числе и значительно упростить руководителям подразделений обязанности по ведомственному контролю деятельности [7]. К примеру, сегодня невозможно представить, как рядовому эксперту, служащему удалённого региона, заинтересовать каким-нибудь новейшим в его практике криминалистическим объектом специалистов из ЭКЦ МВД России.

Сегодня обслуживанием и разработкой данной системы занимается центр научно-технического обеспечения ИСОД МВД России (ЦНТОИ) ФКУ «Научно-производственное объединение “Специальная техника и связь" МВД России» [8], и мы считаем, что его специалистам необходимо обратить внимание на указанные в настоящей статье предложения, относящиеся к методическому обеспечению служебной деятельности ЭКЦ МВД России, так как в настоящее время ИСОД МВД России направлено на комплексное развитие и совершенствование технологий и функций автоматизации и информатизации МВД России [9].

Предложенные в статье изменения ИСОД МВД России, по нашему мнению, благоприятно повлияют и на весь процесс использования специальных знаний сотрудниками подразделений МВД России, начиная использования актуальных современных достижений криминалистики. Также считаем, что в случае создания подобных предлагаемому в статье виртуальному личному кабинету эксперта-криминалиста у МВД появится реальная возможность для автоматического составления реестров судебных экспертов в соответствии с имеющимися подтвержденными допусками на самостоятельное производство судебных экспертиз, а также анализа возможностей производства тех или иных нестандартных экспертиз и исследований в регионах, требующих привлечения либо использования технического потенциала сторонних организаций. После появления таких возможностей у правоохранительной системы МВД России сотрудники следственных подразделений МВД, к примеру, смогут с самого начала, ещё на этапе назначения судебной экспертизы, выбрать то экспертное подразделение системы ЭКЦ МВД России, которое с большой вероятностью возьмётся за производство назначенных экспертиз и исследований. 


\section{Список литературь}

1. Арбузов П. В., Гуде С. В., Карпика А. Г. Вопросы интеграции информационных ресурсов вузов МВД России в ИСОД // Юристъ-правоведъ. - 2014. - № 2 (63). - С. 17-20.

2. Аминев Ф. Г. Судебно-экспертная деятельность в Российской Федерации: Современные проблемы и пути их решения : дис. ... д-ра юрид. наук: 12.00.12 / Аминев Фарит Гизарович. - Уфа, 2016. - 482 c. - С. 208.

3. Савельева Н. В., Савельев В. А. О необходимости повышения уровня профессиональной подготовки экспертов в условиях дифференциации и интеграции научных знаний [Электронный ресурс] // Политематический сетевой электронный научный журнал Кубанского государственного аграрного университета. - 2017. - № 132. - С. 316-323.

4. Семенов Е. Ю. Интегрированная мультисервисная телекоммуникационная система как основа функционирования ИСОД / Процессы информационного обмена в деятельности правоохранительных органов: современное состояние и перспективы совершенствования : сб. науч. ст. / под ред. Л. Д. Матросовой [и др.]. - Орел: Орловский юридический институт МВД России имени В.В. Лукьянова, 2015. - С. 5-9.

5. Леднев К. Ю. ИСОД МВД России и основной элемент инфраструктуры - ЕИС ЦОД // Информационные технологии, связь и защита информации МВД России - 2012 : сб. материалов. - С. $25-27$. - Режим доступа: https://mvd.informost.ru/2012/pdf/part1/1-7.pdf (дата обращения: 04.01.2018).

6. Семёнов Е. Ю. Перспективы развития ИСОД МВД России // Научный вестник Орловского юридического института МВД России имени В.В. Лукьянова. - 2017. - № 3 (72). - С. 135-137.

7. Суглобов A. Е., Барикаев E. Н. Развитие информационно-телекоммуникационной системы ведомственного контроля МВД России (в рамках ИСОД) // Вестник СамГУПС (Самарский государственный университет путей сообщения). - 2014. - № 4 (26). -С. 24-27.

8. Шурховецкий Г. Н. Безопасность информационного обеспечения экспертной и следственной деятельности МВД РФ // Актуальные вопросы инженерно-технических экспертиз : материалы Всероссийской научно-практической конференции. - Иркутск: Восточно-Сибирский институт МВД России, 2018. - С. 14-22.

9. Мачтаков С. Г., Питолин М. В. Единая система информационно-аналитического обеспечения деятельности (ИСОД) МВД России // Пожарная безопасность: проблемы и перспективы. - 2016. - № 1 (7). - С. 156-158.

\section{References}

1. Arbuzov P. V., Gude S. V., Karpika A. G. Voprosy integratsii informatsionnykh resursov vuzov MVD Rossii v ISOD // Yurist-pravoved. - 2014. - № 2 (63). - S. 17-20.

2. Aminev F. G. Sudebno-ekspertnaya deyatel'nost' v Rossiyskoy Federatsii: Sovremennyye problemy i puti ikh resheniya : dis. ... d-ra yurid. nauk: 12.00.12 / Aminev Farit Gizarovich. - Ufa, 2016. - 482 s. - C. 208.

3. Savel'yeva N. V., Savel'yev $V$. A. O neobkhodimosti povysheniya urovnya professional'noy podgotovki ekspertov $\mathrm{v}$ usloviyakh differentsiatsii i integratsii nauchnykh znaniy [Elektronnyy resurs] // Politematicheskiy setevoy elektronnyy nauchnyy zhurnal Kubanskogo gosudarstvennogo agrarnogo universiteta. - 2017. - № 132. - S. 316-323.

4. Semenov Ye. Yu. Integrirovannaya mul'tiservisnaya telekommunikatsionnaya sistema kak osnova funktsionirovaniya ISOD / Protsessy informatsionnogo obmena v deyatel'nosti pravookhranitel'nykh organov: sovremennoye sostoyaniye i perspektivy sovershenstvovaniya : sb. nauch. st. / pod red. L. D. Matrosovoy [i dr.]. - Orel: Orlovskiy yuridicheskiy institut MVD Rossii imeni V.V. Luk'yanova, 2015. - S. 5-9.

5. LednevK. Yu. ISOD MVD Rossii i osnovnoyelement infrastruktury-YEISTSOD//Informatsionnyye tekhnologii, svyaz' i zashchita informatsii MVD Rossii - 2012 : sb. materialov. - S. 25-27. - Rezhim dostupa: https://mvd.informost.ru/2012/pdf/part1/1-7.pdf (data obrashcheniya: 04.01.2018).

6. Semenov Ye. Yu. Perspektivy razvitiya ISOD MVD Rossii // Nauchnyy vestnik Orlovskogo yuridicheskogo instituta MVD Rossii imeni V.V. Luk'yanova. - 2017. - № 3 (72). - S. 135-137.

7. Suglobov A. Ye., Barikayev Ye. N. Razvitiye informatsionno-telekommunikatsionnoy sistemy vedomstvennogo kontrolya MVD Rossii (vramkakh ISOD) //Vestnik SamGUPS (Samarskiygosudarstvennyy universitet putey soobshcheniya). - 2014. - № 4 (26). -S. 24-27.

8. Shurkhovetskiy G. N. Bezopasnost' informatsionnogo obespecheniya ekspertnoy i sledstvennoy deyatel'nosti MVD RF // Aktual'nyye voprosy inzhenerno-tekhnicheskikh ekspertiz: materialy Vserossiyskoy nauchno-prakticheskoy konferentsii. - Irkutsk: Vostochno-Sibirskiy institut MVD Rossii, 2018. - S. 14-22.

9. Machtakov S. G., Pitolin M. V. Yedinaya sistema informatsionno-analiticheskogo obespecheniya deyatel'nosti (ISOD) MVD Rossii // Pozharnaya bezopasnost': problemy i perspektivy. - 2016. - № 1 (7). S. $156-158$.

(с) Жидков Д.Н., 2019

Статья поступила в редакцию 04.06.2019 г. 